1 Barnett HJM. The pathophysiology of transient cerebral ischemic attacks; therapy with platelet antiaggregants. Med Clin North Am 1979;63:649-79

2 Marshall J. The management of cerebrovascular diseases. Oxford: Blackwell Scientific, 1976:57-9.

3 Herndon RII, Nelson JN, Johnson JF, Meyer JS. Thrombolytic treatment in cerebrovascular thrombosis. In: Macmillan RL, Mustard $\mathrm{JF}$, eds. Anticoagulants and fibrinolysis. Philadelphia: Lea and Febiger, 1961:154-64.

4 Mever JS, Herndon RM, Gotoh F, Tazaki Y, Nelson JN, Johnson JF. Therapeutic thrombolysis. In: Millikan $\mathrm{CH}$, Siekert RG, Whisnant Therapeutic thrombolysis. In: Millikan $\mathrm{CH}$, Siekert RG, Whisnant
$\mathrm{JP}$, eds. Cerebral vascular disease. Third Princeton conference. New JP, eds. Cerebral vascular disease. Third
York: Grune and Stratton, 1961:160-77.

5 Mever JS, Gilroy J, Barnhart ME, Johnson JF. Therapeutic thrombolysis in cerebral thromboembolism: randomized evaluation of intravenous streptokinase. In: Millikan CH, Siekert W, Whishant JP, eds. Cerebral I'ascular Diseases. Fourth Princeton conference. New York: Grune and Stratton, 1964:200-13.

6 Fletcher AP, Alkjearsig N, Lewis M, et al. A pilot study of urokinase therapy in cerebral infarction. Stroke 1976;7:135-42.

7 Del Zoppo GJ, Zeumer H, Harker LA. Thrombolytic therapy in stroke. Stroke 1986; 17:595-607.

Sloan MA. Thrombolysis and stroke. Past and future. Arch Neurol 1987;4:748-68

9 Dodson RF, Tagashira Y, Kawamura Y, Wai-Fong Chu L. Morphological responses of cerebral tissues to temporary ischemia. Can $\mathcal{f}$ Veurol Sci 1975:2:173-7.

10 Zeumer H. Survev of progress: vascular recanalizing techniques in interventional neuroradiology. F Neurol 1985;231:287-94.

11 Matsuo $O$, Rijken DC, Collen D. Thrombolysis by human tissue plasminogen activator and urokinase in rabbits with experimental pulmonary embolus. Nature 1981;291:590-1.

12 Collen D, Stassen JM, Verstraete M. Thrombolysis with human extrinsic (tissue-type) plasminogen activator in rabbits with experimental jugular vein thrombosis. Effect of molecular form and dose of activator, age of the thrombus and route of administration. $f$ Clin Invest 1983;71:368-76.

13 TIMI Study Group. The thrombolysis in myocardial infarction (TIMI) trial. Phase I findings. N Engl f Med 1985;312:932-6.

14 Verstraete $M$, Bernard $R$, Bory $M$, et al. Randomized trial of intravenous recombinant tissue-type plasminogen activator versus intravenous streptokinase in acute myocardial infarction: report from the European Cooperative Study Group for Recombinant Tissue-type Plasminogen Activator. Lancet 1985; i:842-7.

15 Verstraete M, Bleifeld W, Brower RW, et al. Double-blind randomized trial of intravenous tissue-type plasminogen activator versus placebo in acute myocardial infarction. Lancet 1985;ii:965-9.

16 Zivin J. Tissue plasminogen activator therapy for embolic stroke. Stroke 986;17:133.

17 Del Zoppo GJ, Copeland BR, Waltz TA, et al. Thrombolytic therapy in a baboon model of acute stroke. Stroke 1986:17(suppl 1):10.

8 Papadopoulos SM, Chandler WF, Salamat MS, Topol EJ, Sackellares JC. Recombinant human tissue-type plasminogen activator therapy in acute thromboembolic stroke. ${ }_{2}$ f Neurosurg 1987;67:394-8.

19 Henze Th, Boeer A, Tebbe U, Romatowski J. Lysis of basilar artery occlusion with tissue plasminogen activator. Lancet 1987;ii:1391.

20 Clauss A. Gerinnungsphysiologische Schnellmethode zur Bestimmung des Fibrinogens. Acta Haematol (Basel) 1957;17:237-46.

21 Petito CK. Early and late mechanisms of increased vascular permeability following experimental cerebral infarction. $\mathcal{F}$ Neuropathol Exp Neurol 1979;38:222-34.

22 Brott T, Haley EC, Levy DE, et al. Very early therapy for cerebral infarction with tissue plasminogen activator [Abstract]. Stroke 1988; infarction

(Accepted 18 October 1988)

\title{
Intravenous methylprednisolone in the treatment of Graves' ophthalmopathy
}

\author{
Pat Kendall-Taylor, Alex L Crombie, Anthea M Stephenson, Mary Hardwick, Keith Hall
}

Departments of Medicine, Ophthalmology, and Human Genetics, University of Newcastle upon Tyne

Pat Kendall-Taylor, MD, professor of endocrinology

Alex L Crombie, FRCSFD, professor of ophthalmology Anthea M Stephenson, BSC, data analyst

Mary Hardwick, MSC, research assistant

\section{Department of}

Neuroradiology,

Newcastle General

Hospital, Newcastle upon

Tyne NE4 6BE

Keith Hall, FRCR, consultant neuroradiologist

Correspondence to:

Professor P Kendall-Taylor,

Ward 10 Office, Roval

Victoria Infirmary,

Newcastle upon Tyne

NE1 4LP.

\section{Abstract}

Eleven euthyroid patients with severe Graves' eye disease were treated with intravenous methylprednisolone and followed up for six months or more by ophthalmological assessment, orbital computed tomography (CT), photographs, and antibody measurements. Papilloedema resolved in the single patient in whom it was present; visual acuity was abnormal in seven eyes initially and in only one eye after treatment; the intraocular pressure differential, which reflects muscle dysfunction, was initially abnormal in 18 eyes but showed a progressive and distinct improvement; nine patients showed substantial improvement in inflammatory signs. Exophthalmos improved early after treatment, but this improvement was not maintained. Orbital CT showed a pronounced reduction in the bulk of eye muscles after treatment in eight of nine patients. Autoantibodies to the thyroid stimulating hormone receptor declined. Adverse effects were trivial. Thus eight patients showed a clear response to intravenous methylprednisolone as judged by ophthalmic assessment and CT scan. The two patients who showed little response and one who had none all had a long history (more than a year) of ophthalmopathy. Results were better than those with oral steroids and adverse effects less.

Treatment of Graves' eye disease is more likely to be effective if given early; patients should be referred promptly to specialist centres, where treatment with intravenous methylprednisolone should be considered.

\section{Introduction}

Graves' ophthalmopathy is a distressing condition which may give rise to diplopia and blindness as well as to unsightly inflammation and proptosis. Treatment of severe ophthalmopathy is not satisfactory. Surgical treatment (orbital decompression) may be employed in centres where it is available, but it is not without complications. Most doctors would prefer medical treatment if possible, and as Graves' ophthalmopathy is almost certainly an autoimmune disease, attempts have been made to suppress the immune response - for example, with steroids, cyclosporin $\mathrm{A}$, or azathioprine - to modulate it by plasma exchange, or to suppress inflammation by orbital irradiation. The most effective of the drugs used for immune suppression are undoubtedly steroids, but to be effective high dosage is necessary, when the frequency and severity of adverse effects are a serious disadvantage. Moreover, the result of steroid treatment with regard to the eyes is usually one of modest improvement rather than reversal of disease.

Large dose bolus intravenous methylprednisolone has been used to good effect in other autoimmune diseases-for example, glomerulonephritis ${ }^{1.3}-$ and we therefore decided to try it in autoimmune ophthalmopathy. As Graves' ophthalmopathy is a nonfatal disease and intravenous methylprednisolone is itself not without risk, we cautiously employed a lower total dose schedule than has been used for either graft rejection or glomerulonephritis. This paper reports on 11 patients treated in this way, who were followed up for six months or more. Measurements were made of different aspects of the disease for statistical assessment and these compared with the changing serum autoantibody activities.

\section{Patients and methods}

The 11 patients (six women, five men) were aged 28 68 years (mean 52.6 ) and had had their eye disease for three to 72 months. Table I gives details of the patients at entry to the study. Only two patients had received any previous immunosuppressive treatment. All were euthyroid at the time treatment was begun and 


\begin{tabular}{|c|c|c|c|c|c|c|c|c|c|c|c|c|}
\hline \multirow{2}{*}{$\begin{array}{c}\text { Case } \\
\text { No }\end{array}$} & \multirow{2}{*}{$\begin{array}{c}\text { Age } \\
\text { (years) }\end{array}$} & \multirow[b]{2}{*}{ Sex } & \multirow{2}{*}{$\begin{array}{l}\text { Duration of } \\
\text { eye disease } \\
\text { (months) }\end{array}$} & \multirow[b]{2}{*}{ Present drugs } & \multirow[b]{2}{*}{ Previous treatment } & \multirow{2}{*}{$\begin{array}{l}\text { Thyroid } \\
\text { microsomal } \\
\text { antibody } \\
\text { titre }\end{array}$} & \multirow{2}{*}{$\begin{array}{l}\text { Thyroid stimulating } \\
\text { hormone binding inhibiting } \\
\text { immunoglobulin index } \\
\text { (normal range }<17)\end{array}$} & \multirow{2}{*}{$\begin{array}{l}\text { Ophthalmopathic } \\
\text { immunoglobulin } \\
(\text { normal range }<0 \cdot 30)\end{array}$} & \multicolumn{3}{|c|}{ HLA } & \multirow{2}{*}{$\begin{array}{l}\mathrm{P} \\
\text { blood } \\
\text { group }\end{array}$} \\
\hline & & & & & & & & & A & B & DR & \\
\hline 1 & 64 & $M$ & 12 & Carbimazole + thyroxine & Nil & Negative & $14 \cdot 2$ & 0.55 & 1,2 & 8,44 & 3,4 & P. \\
\hline 2 & 64 & $M$ & 3 & Carbimazole & Nil & Negative & $27 \cdot 6$ & Undetectable & 2,10 & 5,18 & 4 & Not done \\
\hline 3 & 50 & $\mathrm{~F}$ & 6 & Carbimazole + propranolol & Nil & $>1 / 1600$ & $89 \cdot 9$ & Undetectable & 9,28 & 15,18 & 4,5 & $\mathrm{P}$ \\
\hline 4 & 46 & $\mathbf{F}$ & 48 & Thyroxine & ${ }^{114} \mathrm{I}(1982)$ & & & & & & & \\
\hline & & & & & cyclosporin (1984) & $1 / 800$ & $43 \cdot 6$ & Undetectable & 2,10 & 8,40 & 3,4 & p. \\
\hline 5 & 68 & $M$ & 4 & Thyroxine & ${ }^{13} \mathrm{I}(1985)$ & $>1 / 1600$ & $72 \cdot 1$ & 0.62 & 2,3 & 7,8 & 3,6 & P. \\
\hline 6 & 62 & $M$ & 72 & Oxytetracycline & ${ }^{11} \mathbf{I}(1977)$ & Negative & $94 \cdot 5$ & $1 \cdot 00$ & w19, 28 & 15,44 & 4 & $\mathrm{P}$ \\
\hline 7 & 55 & $\mathrm{~F}$ & 7 & Nil & Nil & Negative & $12 \cdot 1$ & 0.62 & 2,8 & 8,13 & 3,7 & $\mathrm{P}$ \\
\hline 8 & 54 & $\mathrm{~F}$ & 3 & Nil & Nil & $1 / 1600$ & $70 \cdot 4$ & Undetectable & 3,9 & 7,40 & $4, w 6$ & $\mathrm{p}$ \\
\hline 9 & 38 & $\mathrm{~F}$ & 9 & Carbimazole + thyroxine & Nil & $>1 / 1600$ & $61 \cdot 9$ & Undetectable & 2,3 & 7,15 & 2,4 & $\mathrm{p}$ \\
\hline 10 & 28 & $\mathrm{~F}$ & 7 & Carbimazole + thyroxine & Nil & Negative & $25 \cdot 6$ & Undetectable & 1,10 & 5,8 & 3,5 & $\mathrm{p}$ \\
\hline 11 & 50 & $M$ & 18 & Nil & Prednisolone & Negative & 6.6 & Undetectable & 2,3 & 14,40 & 1 & $\mathrm{P}$ \\
\hline
\end{tabular}

remained euthyroid throughout. Five patients were already stabilised taking carbimazole, two were stable taking thyroxine replacement for hypothyroidism after radioiodine treatment, and three had ophthalmic Graves' disease - that is, they were euthyroid with no past or present thyroid dysfunction.

Immunological and genetic assessment-HLA typing (A, B, and DR) was performed on all patients. Blood was taken for analysis of a range of genetic markers including P blood group, which we have shown to be significantly associated with Graves' ophthalmopathy. ${ }^{4}$ Thyroid stimulating hormone binding inhibiting immunoglobulin index was measured as described. ${ }^{5}$ Ophthalmopathic immunoglobulin was measured by enzyme linked immunosorbent assay (ELISA). ${ }^{6}$ Thyroid microsomal antibodies were measured with the haemagglutination test kit (Fujizoki Co, Tokyo). Blood samples were taken from patients at each attendance, and serial samples from an individual patient always measured together in the same assay.

Ophthalmological assessment was done by the same observer (ALC) throughout. Periorbital oedema and conjunctival inflammation and oedema were noted. Fundi were examined; visual acuity was tested with a Snellen chart and the measurement converted to the international classification. The palpebral apertures were measured in the midline. Exophthalmos was measured with a Hertel exophthalmometer. Intraocular pressures were measured with an applanation tonometer in the primary position and on upward or attempted upward gaze and the difference between these two measurements calculated for each eve. A Hess chart was included when appropriate. The eyes were photographed in the primary position and on upward and lateral gaze.

Neuroradiological assessment-Computed tomograms $(\mathrm{CT})$ of the orbits were obtained in the axial or coronal plane (sometimes both planes) before and after treatment. Scanners used were an EMI 1010, Picker $1200 \mathrm{SX}$, and IGE 9800 . Contrast enhancement was not employed. To assess changes in the scan each of the rectus muscles of both orbits was separately graded for enlargement $(0=$ normal; $1=$ slight enlargement; $2=$ moderate enlargement; $3=$ pronounced enlargement) and a total score obtained. All scans were evaluated blindly by a single observer $(\mathrm{KH})$ - that is, without knowledge of the date of the scan (before or after treatment) or of details of the patient.

Treatment protocol-Patients were admitted to hospital for treatment with intravenous methylprednisolone and had a full clinical examination including electrocardiography before treatment. Only patients with no evidence of cardiovascular disease were admitted to the study. Methylprednisolone was given as $0.5 \mathrm{~g}$ in $200 \mathrm{ml}$ isotonic saline infused over 30 minutes. Patients were carefully observed over the next 48 hours and a further $0.5 \mathrm{~g}$ given. The day after the second dose patients were discharged home and began oral prednisolone in a maintenance dosage of
$40 \mathrm{mg}$ daily together with prophylactic ranitidine and potassium supplementation. Prednisolone was reduced gradually to $10 \mathrm{mg}$ daily by four weeks and ranitidine and potassium (Slow-K) stopped after one month. Further reduction and discontinuation of prednisolone depended on the clinical assessment at follow up visits.

Follow up-During the six months or more after the infusions of methylprednisolone patients were seen regularly in a combined clinic by an ophthalmologist and a thyroidologist. Detailed reassessment of ophthalmological state and measurements of thyroid hormones and autoantibodies were carried out at one, four, eight, 12, and 24 weeks. Repeat photographs were taken at the end of the study period.

Statistical analysis - Values obtained after treatment were compared with pretreatment values by using Student's paired or unpaired $t$ test or Wilcoxon's signed rank test, as appropriate. The intraocular pressure differential is the difference between the intraocular pressure on upgaze and that in the primary position. In several patients the eyes were unequally affected and therefore calculations were based on numbers of eyes (initially 22 ) rather than numbers of patients. Spearman's rank correlations and the $\chi^{2}$ test were applied when indicated.

\section{Results}

Three patients (cases 4,6 , and 11 ) were judged to have shown little or no response to treatment. One of these (case 6) discontinued treatment and withdrew from the study after four weeks. All three patients had had their eye disease for more than 12 months, whereas in all other patients the condition had been present for less than 12 months (table I). Thyroid function remained normal throughout without need for any change in treatment apart from minor adjustments of dosage.

\section{OPHTHALMOLOGICAL ASSESSMENT}

Table II gives the results of ophthalmological assessment initially and after six months.

Corrected visual acuity (table II) was initially reduced in seven of the 22 eyes and improved rapidly in response to intravenous methylprednisolone. Improvement usually occurred within 24 hours and certainly in less than seven days in those in whom it had been impaired. Visual acuity was restored to normal in all except one patient (case 5), who had bilateral papilloedema with choroidal folding and an initial visual acuity of $6 / 24$, which improved to 6/9; the fundal changes resolved slowly over six weeks. No other fundal or disc changes were seen in the rest of the series despite the lower visual acuities.

Exophthalmos $(>20 \mathrm{~mm})$ was present in 12 eyes initially with readings ranging from $15 \mathrm{~mm}$ to $28 \mathrm{~mm}$. An improvement in exophthalmos was seen within a few days of treatment but was followed by return to the 


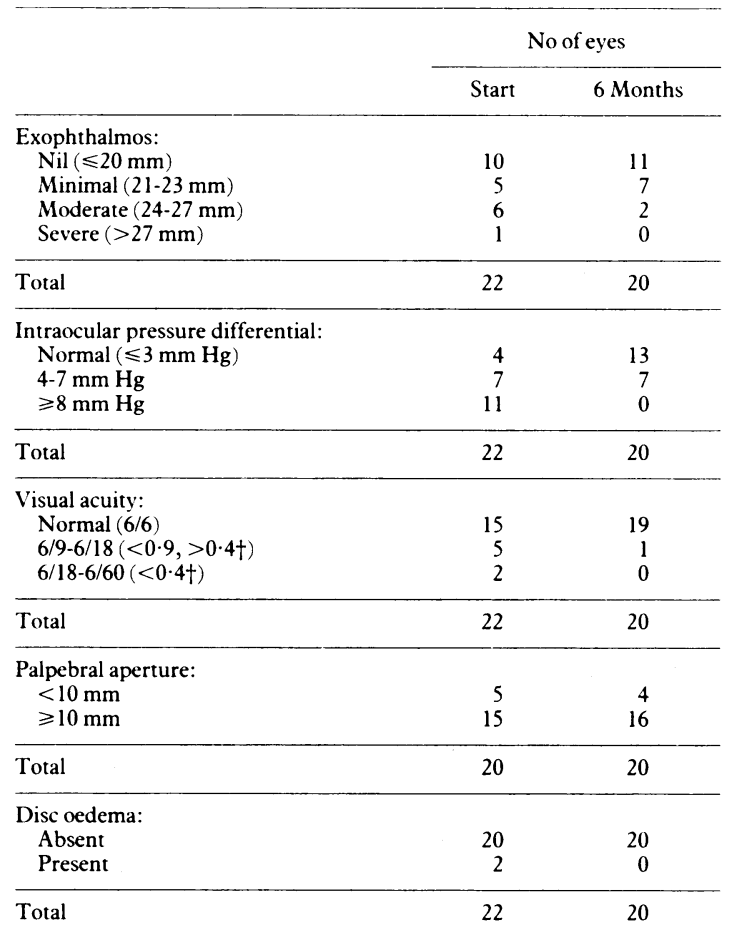

*Case 6 excluded from follow up data (patient withdrew from study after four weeks).

tFigures in parentheses are international equivalents.

pretreatment reading by about eight weeks; at the end of the study there was no significant improvement (Wilcoxon test; eyes without exophthalmos excluded) (fig 1 ; table II).

The readings for palpebral apertures were not significantly changed after six months (Wilcoxon's signed rank test).

In only four eyes was the intraocular pressure differential not increased initially, and in 11 it was much increased. At the end of the study 13 eyes were normal and none showed a pronounced increase (table II). The change from the pretreatment value was highly significant by the $\chi^{2}$ test. During treatment there was a gradual reduction in the pressure differential in all eyes (fig 2). The mean measurement before treatment was $7 \cdot 41 \mathrm{~mm}(\mathrm{SD} 0 \cdot 81)$ and six

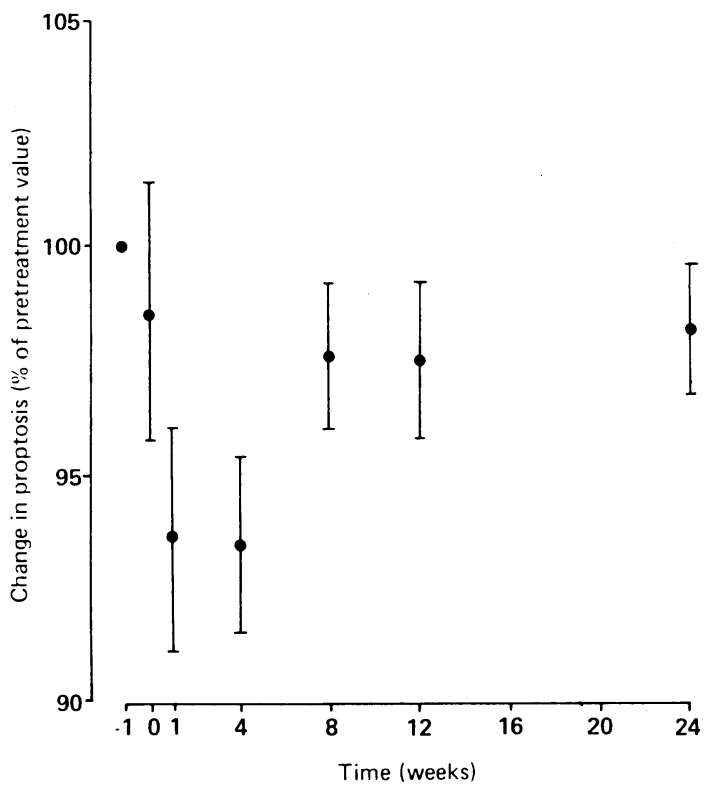

FIG 1-Change in proptosis after treatment with intravenous methylprednisolone. Measurements are scaled because of wide range of initial values, such that each reading is expressed as percentage of pretreatment reading. Points are means and $S D$ (bars) for 18 eyes months after treatment the mean reading was $3.33 \mathrm{~mm}$ $(0 \cdot 50)$. Wilcoxon's signed rank test showed that the improvement after eight weeks was not significant but that after 12 weeks it was significant at $5 \%$ and after six months it was significant at $1 \%$. When measurements in right and left eyes were averaged for each patient the values before and after treatment were $6.41 \mathrm{~mm}$ and $3.25 \mathrm{~mm}$ respectively.

Inflammatory signs consisting of lid oedema, conjunctival oedema, and injection over the insertions of the horizontal recti were present in 10 patients at the initial examination. After treatment nine patients showed a substantial improvement, particularly in relation to conjunctival injection and oedema and injection over the muscle insertions. There was some diminution of periorbital oedema, but this was complicated in most cases by fat herniation into the upper lids in particular.

Five patients showed pronounced muscle dysfunction in both horizontal and vertical movements. After the treatment period three patients showed an improvement in muscle function with loss of diplopia. Two patients, however, remained unchanged and required extraocular muscle surgery.

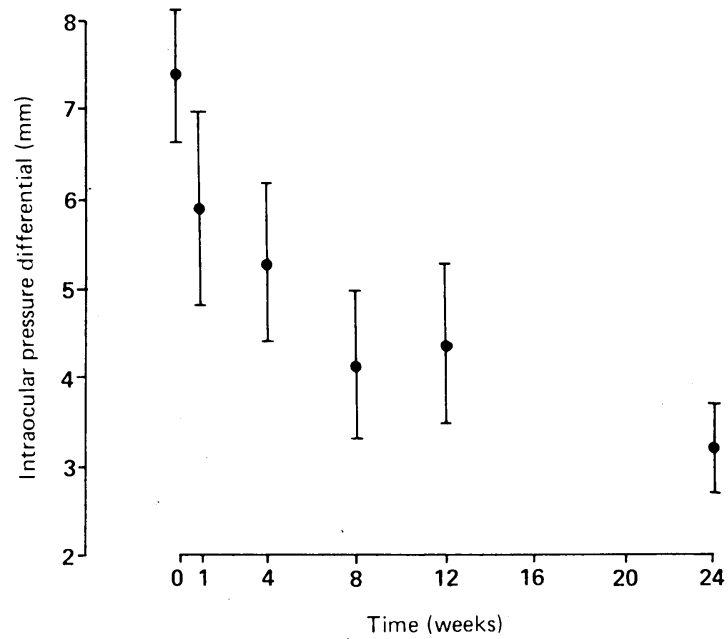

FIG 2-Change in intraocular pressure differential in response to treatment. (Intraocular pressure differential is difference between intraocular pressure on upgaze or attempted upgaze and intraocular pressure in primary position.) Points are means and SD (bars) for 18 eyes

\section{ANTIBODY STUDIES}

Thyroid stimulating hormone binding inhibiting immunoglobulin index was raised in eight of the 11 patients initially and declined during treatment; in the other three patients values were in the normal range throughout. The thyroid stimulating hormone binding inhibiting immunoglobulin index at weeks $8-12$ was significantly less than the starting value $(p<0.025$; paired $t$ test), but the difference was not significant at week 4 ; in three patients thyroid stimulating hormone binding inhibiting immunoglobulin became undetectable during treatment.

Ophthalmopathic immunoglobulin was positive in only four patients initially. It became undetectable within one month after methylprednisolone in case 1 and did not reappear. In the other three patients titres declined initially after methylprednisolone but thereafter did not change appreciably.

Microsomal antibodies were initially detectable in five patients and six months after treatment were still present, though in slightly lower titre in four.

\section{SPEARMAN'S CORRELATION}

Spearman's rank correlations were carried out with all measurements on all patients. Visual acuity, 
palpebral aperture, intraocular pressure differential, and thyroid stimulating hormone binding inhibiting immunoglobulin all showed significant correlations with time since treatment $\left(r_{s}=0.35, p<0.0001\right.$; $r_{s}=-0.12, p=0.004 ; \quad r_{s}=-0.40, p<0.0001 ;$ and $r_{s}=-0.43, p<0.001$, respectively). Visual acuity correlated negatively with palpebral aperture, intraocular pressure differential, and thyroid stimulating hormone binding inhibiting immunoglobulin $\left(r_{s}=-0.35, p<0.0001 ; r_{s}=-0.35, p<0.0001\right.$; and $\left.r_{s}=-0.44, p<0.0001\right)$. The changes in palpebral aperture correlated with intraocular pressure differential $\left(r_{s}=0.21, p<0.003\right)$ and with exophthalmos $\left(r_{s}=0.47, p<0.0001\right)$.

\section{NEURORADIOLOGICAL ASSESSMENT}

Nine patients had CT scans before and after treatment. All the scans were abnormal before treatment with varying degrees of enlargement of one or more extraocular muscles. The medial rectus muscles were affected most commonly, whereas the lateral rectus muscles were enlarged in only three patients. In all but one of these nine cases there was a definite reduction in muscle size, though the degree of improvement was variable. The mean scores before and after treatment were $8.0($ SEM 1.4) and 3.9 (SEM: 0.9 ) respectively. In only one patient (case 2 ; fig 3 ) did extraocular muscle size return completely to normal after severe enlargement (pretreatment score 13).

\section{ADVERSE EFFECTS}

Adverse effects were a weight gain of around $3 \mathrm{~kg}$ in four patients, transient impairment of glucose tolerance in one, mild dyspepsia in one, and irritability in one.

\section{Discussion}

In this series of 11 patients treated with intravenous methylprednisolone for severe Graves' eye disease three patients who had had their disease for more than a year showed little or no response. The remaining patients showed an overall clear cut response, which was most apparent from measurements of the intraocular pressure differential and visual acuity. The response was often quite dramatic by 24 hours after the first dose, both when assessed subjectively and when evaluated objectively; this was most noticeable as a decrease in inflammation and proptosis with an improvement in visual acuity and therefore possibly represented a decrease in orbital oedema rather than immunosuppression at that stage. We decided to evaluate the late response, as the long term result is the more important; but for patients with congestive ophthalmopathy, fortunately rare (case 5), the ability to obtain rapid improvement is plainly an advantage.

There are two main problems in designing a trial of treatment of Graves' ophthalmopathy-namely,

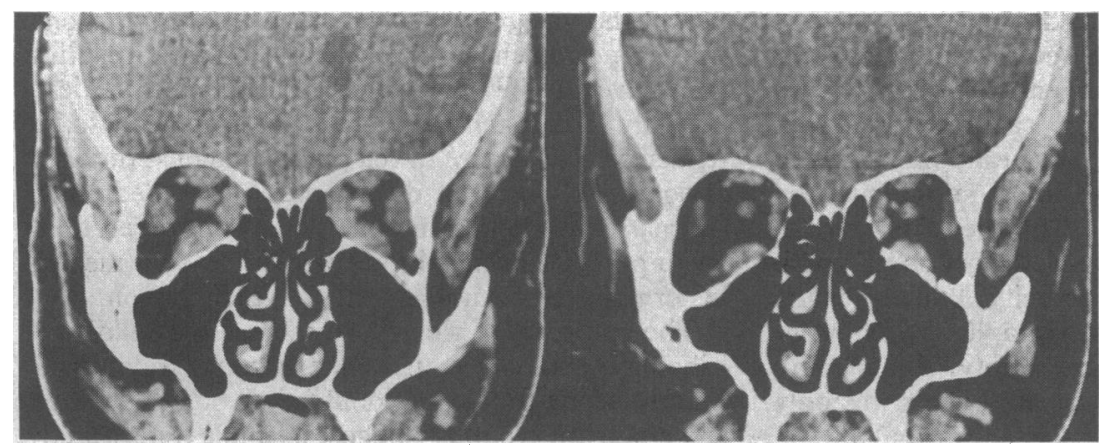

FIG 3-Case 2. Coronal plane CT scans through posterior orbit before (left) and six months after treatment with methylprednisolone (right). Second scan shows pronounced reduction in extraocular muscle size selecting the most appropriate method of assessment and the impossibility of doing a properly controlled trial. Other studies have used an arbitrary index to assess response, ' but we do not think that this is appropriate, as it gives equal weighting to several variables, some of which are less important than others. The most important aspects of treatment are in restoring normal visual acuity, avoiding corneal exposure, and improving double vision. Cosmetic improvement is of secondary importance in the acute phase and is better dealt with surgically later. It therefore follows that the best measures of severity of the disease and of response to treatment are visual acuity and muscle function (Hess chart, intraocular pressure differential, and possibly fields of binocular single vision).

Vertical palpebral aperture does not reflect well the degree of ophthalmopathy, partly because of the difficulty in obtaining an accurate measurement ${ }^{8}$ and also because it is affected by other factors, such as thyroid state, which are independent of true ophthalmopathy. Proptosis, though a more useful measure, is also of limited value and does not necessarily relate to the severity of visual impairment. ${ }^{9}$ The intraocular pressure differential has been considered useful by other workers ${ }^{10-12}$ and is a more sensitive method of detecting Graves' ophthalmopathy than measurement of exophthalmos." Our study shows the usefulness of the intraocular pressure differential in determining response to treatment, and it also correlated well with the patients' own assessments.

It is clear that intravenous methylprednisolone is effective, but it is less easy to make definite recommendations about its place in the treatment of Graves' ophthalmopathy. As ophthalmopathy severe enough to warrant immunosuppressive treatment occurs in only $2-3 \%$ of patients with Graves' disease direct comparisons with high dose oral steroids or with cyclosporin would require large scale multicentre trials. We find, however, that oral steroids are of only moderate efficacy; they have delayed effects and frequent adverse effects. This also appears to be the experience of others, ${ }^{1314}$ and many workers have commented on the need for prolonged high dosage with the attendant risks of potentially serious side effects. By using intravenous bolus methylprednisolone a highly immunosuppressive dose of steroid can be given with a considerably reduced risk of adverse effects. Experience with cyclosporin, ${ }^{15}$ plasma exchange, ${ }^{12} 16$ and other immunosuppressive drugs is less satisfactory. ${ }^{17}$ An alternative approach to treatment is with orbital cobalt radiotherapy, total dose $20 \mathrm{~Gy}$ (2000 rads), combined with systemic steroids (70-80 mg prednisolone daily for several weeks)..$^{1418}$

We do not know the precise cause of Graves' ophthalmopathy, though there is good evidence that it results from an autoimmune process. ${ }^{19}$ The antibodies responsible for the hyperthyroidism of Graves' disease, though often found in association with ophthalmopathy, are almost certainly not responsible. ${ }^{20}$ Autoantibodies may be detected against eye muscle in association with Graves' disease, but there is no evidence as yet that they are directly pathogenic. The features of the disease may result from antibody dependent cell cytotoxicity ${ }^{21}$ or from some other unidentified mechanism. It was therefore interesting to record the changing antibody levels in response to treatment; a significant decrease was seen in thyroid stimulating hormone binding inhibiting immunoglobulin, though this needs to be interpreted with care, as four of these patients were also receiving carbimazole, which may itself cause decreased antibody activity. ${ }^{22}$. Ophthalmopathic immunoglobulin disappeared from the serum of one patient 
during the week after methylprednisolone treatment but no change occurred in another patient (case 5), who responded extremely well to treatment. It is impossible to draw conclusions from such small numbers about the possible pathogenic relevance of this antibody.

Now that intravenous methylprednisolone has been shown to be effective the therapeutic schedule needs to be optimised. A modest maintenance dose of oral steroid appeared to be necessary from our preliminary findings in two patients, who after a good response to intravenous methylprednisolone began oral prednisolone $10 \mathrm{mg}$ daily but within a week had reverted to their pretreatment state. We may have been overcautious with the dose of methylprednisolone and possibly repeated doses of methylprednisolone might be preferable. This would best be investigated in a multicentre trial.

In conclusion, intravenous methylprednisolone appears to be an important new approach to the management of Graves' ophthalmopathy. It is probably preferable to other means of treatment for patients with severe disease, and is certainly preferable to very high dose oral prednisolone, giving a better response with fewer adverse effects. Idiosyncratic cardiovascular deaths have been reported and patients should be assessed medically before treatment; for this reason it should be reserved for patients with visual impairment. The rapid response is a useful feature and patients whose visual acuity does not improve after 48 hours may be referred early for surgery. Though numbers in our series were small, we emphasise that the patients who failed to respond were those with the longest history. This agrees with previous studies using other modes of treatment. ${ }^{1516}$ The implication is that patients with Graves' ophthalmopathy should be referred as early as possible to a specialist centre.

Our thanks are due to the medical and nursing staff of the endocrine unit for help with treatment and to colleagues who referred patients to us (Dr W Kelly, Dr P H Carr, Dr E Barnes, Mr R B Cubey, Mr L Singh, Mr R Bosanquet). The work was supported by a project grant from the Medical Research Council.
1 Cole BR, Brocklebank JT, Kienstra RA, et al. "Pulse" methylprednisolone therapy in the treatment of severe glomerulonephritis. I Pediatr 1976;88: 307-14.

2 O'Neill WM, Etheridge WB, Bloomer HA. High dose corticosteroids. Arch Intern Med 1979;139:514-8

3 Short CD, Solomon LR, Gokal R, Mallick NP. Methylprednisolone in patients with membranous nephropathy and declining renal function. $Q \mathcal{J}$ Med 1987;247:929-40.

4 Kendall-Taylor P, Stephenson A, Stratton A, Papiha SS, Perros P, Roberts DF. Differentiation of autoimmune ophthalmopathy from Graves' hyperDF. Differentiation of autoimmune ophthalmopathy from Graves'
thyroidism by analysis of genetic markers. Clin Endocrinol (in press).

5 Taylor JJ, Young ET, Holcombe M, Kendall-Taylor P. Evaluation of TBI activity in untreated Graves' disease using solubilised thyroid membranes. activity in untreated Graves' disease
Ann Clin Biochem 1985;22:366-70.

6 Kendall-Taylor $\mathrm{P}$, Atkinson $\mathrm{S}$, Holcombe $M$. A specific $\mathrm{IgC}$ in Graves ophthalmopathy and its relation to retro-orbital and thyroid autoimmunity Br.Med f 1984;288:1183-6.

7 Donaldson SS, Bagshaw MA, Kriss JP. Supervoltage orbital radiotherapy for Graves' ophthalmopathy. F Clin Endocrinol Metab 1973;37:276-85.

8 Waller RR, Samples JR, Yeatts RP. Eyelid malpositions in Graves' ophthalmopathy. In: Gorman CA, Waller RR, Dyer JA, eds. The eye and orbit in thyroid disease. New York: Raven Press, 1984:263-300.

9 Day RM. Ocular manifestations of thyroid disease. Arch Ophthalmol 1960;64 324-41.

10 Pohjanpelto $P$. The thyroid gland and intraocular pressure: tonographic study of 187 patients with thyroid disease. Acta Ophthalmol 1968;97(suppl): 1-70.

1 Gamblin GT, Harper DG, Galentine P, Buck DR, Chernow B, Eil C. Prevalence of increased intraocular pressure in Graves' disease: evidence of frequent subclinical ophthalmopathy. $N$ Engl f Med 1983;308:420-4.

12 Kelly W, Longson D, Smithard D, et al. An evaluation of plasma exchange for Graves' ophthalmopathy. Clin Endocrinol 1983;18:485-93.

13 Hoffenberg R, Jackson WPU. Adrenocortical steroids in malignan exophthalmos. Lancet $1958 ; \mathrm{i}: 693-5$

14 Bartalena L, Marcocci C, Chiovato M, et al. Orbital cobalt irradiation combined with systemic corticosteroids for Graves' ophthalmopathy comparison with systemic corticosteroids alone. $\mathcal{F}$ Clin Endocrinol Metab 1983;56:1139-44.

15 Jacobson DH, Gorman CA. Endocrine ophthalmopathy: current ideas concerning etiology, pathogenesis and treatment. Endocr Rev 1984;5: 200-20.

16 Weetman AP, McGregor AM, Ludgate M, et al. Cyclosporin improves Graves' ophthalmopathy. Lancet 1983;ii:486-9.

17 Glinoer D, Etienne-Decerf J, Schrooven M, et al. Beneficial effects of intensive plasma exchange followed by immunosuppressive therapy in severe Graves' ophthalmopathy Acta Endocrinol 1986;111:30-8.

18 Marcocci $C$, Bartalena L, Panicucci $M$, et al. Orbital cobalt irradiation combined with retrobulbar or systemic corticosteroids for Graves' ophthalmopathy: a comparative study. Clin Endocrinol 1987;27:33-42.

19 Kendall-Taylor P. The pathogenesis of Graves' ophthalmopathy. Clin Endocrinol Metab 1985;14:331-49.

20 Teng CS, Yeung RTT. Changes in thyroid stimulating antibody activity in Graves' disease treated with antithyroid drug and its relationship to relapse: a prospective study. $\mathcal{F}$ Clin Endocrinol Metab 1980;50:144-7.

21 Wang PW, Hiromatsu Y, Laryea E, Wosu L, How J, Wall JR. Immunologically mediated cytotoxicity against human eye muscle cells in Graves' ophthalmopathy. 7 Clin Endocrinol Metab 1986;63:316-22.

22 McGregor AM, Petersen MM, McLachlan SM et al. Carbimazole and the autoimmune response in Graves' disease. N Engl f.Med 1980;303:302-7.

(Accepted 21 October 1988)
Epidemiology and Health Care Research, University of Limburg, PO Box 616, 6200 MD Maastricht, The Netherlands

Paul Knipschild, MD, professor of epidemiology

\title{
Looking for gall bladder disease in the patient's iris
}

\author{
Paul Knipschild
}

\begin{abstract}
In alternative health care iridology is used as a diagnostic aid. The diagnosis of gall bladder disease was used to study its validity and interperformer consistency. The presence of an inflamed gall bladder containing gall stones is said to be easily recognised by certain signs in the lower lateral part of the iris of the right eye. Stereo colour slides were made of the right eye of 39 patients with this disease and 39 control subjects of the same sex and age. The slides were presented in a random order to five leading iridologists without supplementary information. The prevalence of the disease was estimated at $56 \%$. The median validity was $51 \%$ with $54 \%$ sensitivity and $52 \%$ specificity. These results were close to chance validity (iota $=0.03$ ). None of the iridologists reached a high validity. The median interperformer consistency was $60 \%$. This was only slightly higher than chance consistency $(x=0 \cdot 18)$.

This study showed that iridology is not a useful diagnostic aid.
\end{abstract}

\section{Introduction}

Many parts of the human body are projected in the brain. ' Some people believe that projection also exists in other organs - for example, the tongue, feet, ears. ${ }^{2}$ In 1881 von Péczely wrote a book on diagnosis using the eye, in which he gave a schematic representation of the topography of the organs in the iris. Some people now believe that many diseases manifest themselves in the iris, ${ }^{3}$ which is supposed to indicate not only the existence of certain diseases but also the tendency for their development ("constitution"). Iridology is practised on a large scale especially in alternative medicine, in which it is considered to be an important diagnostic supplement to the medical history and (conventional) physical examination.

The emphasis of this study was on the validity of iridology and on consistency among iridologists. Because using iridology is doubted on both theoretica and empirical grounds ${ }^{34}$ I chose a simple test: to study patients with an obvious disease that according to iridologists cannot be overlooked-namely gall stones 